\title{
Currículo e globalização: perspectivas e articulações nas relações de poder e de campo científico
}

\author{
Arlindo Soares Albergaria Junior \\ Islanne Ariel Marinho Rufino \\ Luiz Flávio da Silva \\ Magali Amorim Mata \\ Marluce Gavião Sacramento Dias \\ Roseli Garcia Pedretti ${ }^{1}$
}

\section{INTRODUÇÃO}

Pierre Bourdieu, sociólogo, antropologista e filósofo francês, cujo foco de trabalho se constituía na dinâmica do poder em sociedade, particularmente nas sutis formas de como esse poder é transferido para manter-se a ordem social vigente, embasou seus estudos em nomes como Karl Marx, Émile Durkheim, Max Weber e Claude Lévi-Strauss, entre outros expoentes da Sociologia. Bourdieu tem marcante contribuição à Sociologia da Educação, em particular nos estudos simbólicos das formas de capital, de reprodução cultural de campo e da violência.

O conceito de poder simbólico foi abordado pela primeira vez por Bourdieu, como forma de relacionar os vários e diferentes modos de dominação cultural ou social. O poder simbólico pode ser observado em diversas situações da vida quotidiana, e mais particularmente na educação. Inclui ações que possam apresentar discriminação, como observa-se na questão racial ou na questão do gênero. O poder simbólico se faz prevalecer em determinado campo e pressupõe que haja sempre um dominador e um dominado que aceita esta posição em função da troca do valor social que ocorre entre as duas partes. Tal relação, de certa forma, perpetua uma estrutura social pré-existente, servindo-se assim, aos interesses da classe dominante. Este poder simbólico apresenta-se por vezes mais poderoso que a própria violência física e pode aparecer de forma marcante dentro da escola, principalmente através do currículo.

\footnotetext{
${ }^{1}$ Alunos do Programa de Mestrado Profissional em Gestão e Desenvolvimento da Educação Profissional do Centro Estadual de Educação Tecnológica Paula Souza, disciplina Currículos e Programas.
} 
O professor Antonio Flavio Barbosa Moreira é uma referência enquanto pesquisador do campo do currículo, devido sua reconhecida capacidade, por seu diálogo e por suas reflexões, pertinentes às práticas bem como às questões centrais em torno do campo curricular. Tem experiência na área da educação, com ênfase em currículo, atuando principalmente nos seguintes temas: escola, teorias de currículo, prática curricular, história do currículo, multiculturalismo e formação de professores.

Partilha da visão de que o currículo passou a se constituir em uma relação de poder: o currículo deixa de ser uma área somente técnica, assumindo um papel social e cultural, transmitindo visões sociais e particulares, produzindo identidades individuais e sócios particulares. Aspectos epistemológicos precisam conversar com os aspectos pedagógicos conforme as relações de poder presentes na sociedade. Passa a empregar o conceito de campo, campo científico, campo acadêmico e campo currículo como método para se analisar e propor aspectos quando da renovação curricular. Debruçado sobre o conceito de campo científico, conforme formulado por Pierre Bourdieu, facilita a compreensão entre as divergências e as disputas quanto à produção do conhecimento.

Moreira nos traz os conceitos de globalização, a partir de Burbules e Torres (2000), ao relacionar os processos educativos e curriculares ao processo de globalização e seu impacto sobre a construção do currículo especialmente na universidade. A abordagem sociológica e crítica do currículo em Moreira conduz ao entendimento e à compreensão da Sociologia da Educação. $O$ objetivo deste artigo é discorrer sobre a concepção de relação de poder e do campo científico presentes na construção e representatividade do currículo diante da globalização, sobre as articulações existentes entre globalização, relações de poder e o conceito de campo científico, especialmente sob o ponto de vista de Pierre Bourdieu e Moreira.

Indaga-se: tem a globalização impactado a construção de currículos? Estes têm sido de fato construídos pensando-se numa formação de identidade social de forma que seus atores estejam nivelados? Parte-se do pressuposto de que o currículo é um instrumento de poder cujas classes dominantes se prevalecem para difundir sua ideologia.

\section{REFERENCIAL TEÓRICO}




\section{CURRÍCULO E RELAÇÃO DE PODER}

Para Moreira e Tadeu (2013), a questão do currículo merece ser apresentada de modo a fundamentar a posição de Bourdieu: as implicações do currículo relacionam-se claramente à globalização, ao poder e ao campo científico. Os autores abordam o momento em que o currículo passa a ser visto como a possibilidade de se planejar "cientificamente" as atividades pedagógicas de forma a que, ao se controlar tais atividades, possa-se "evitar" que o comportamento e o pensamento do aluno se desviem de metas e dos padrões pré-definidos. (MOREIRA e TADEU, 2013).

Para Moreira (2005), a discussão sobre currículos deve pautar-se sobre os aspectos outorgados pelos processos da globalização, quer econômicos, sociais, político-culturais, quer religiosos ou jurídicos, uma vez que o antagonismo e as contradições desse conjunto, derivado da globalização, atinge a todos propondo consequentemente, uma separação entre uma cultura globalizada e o "resto do mundo". (MOREIRA, 2005, p.3)

Do pós-guerra civil americano, numa sociedade, que passa a ser regida pelo capital industrial, com a substituição do até então sistema de livre competição pelos monopólios, com consequente aumento da produção, o processo produtivo tornou-se não apenas mais complexo como também mais socializado. Os procedimentos administrativos se sofisticam e adquirem cunho científico. A presença do imigrante, entretanto, em solo norte-americano é uma ameaça à hegemonia nacional. Reina uma preocupação quanto à hegemonia nacional norte-americana e consequentemente, uma consolidação cultural carecia de um projeto nacional. A escola passa então a ser vista como o local ideal para se inculcar os valores, as condutas e hábitos tidos como adequados e como ambiente propício para formar as novas gerações ante as transformações econômicas, sociais e culturais necessárias. (MOREIRA e TADEU, 2013).

Apple (2008), pontua que o currículo bem como as questões educacionais, sempre estiveram conectados à história de conflitos de classe, raça, sexo e religião, quer nos Estados Unidos, quer em outros países do mundo. (APPLE, 2008). 
É na escola o lugar a se restaurar a 'homogeneidade' e ensinar à criança imigrante, crenças e comportamentos dignos da sociedade americana. O currículo é visto como artefato social e cultural. O currículo é embricado em relações de poder: transmite visões sociais, particulares interessadas e produz identidades individuais e sociais, particulares, além de ser temporal. Daí a associação do campo do currículo como sendo um instrumento de controle e eficiência social, pois evita que o comportamento e pensamento do aluno se desviem das metas e padrões prédefinidos, o currículo, portanto, como uma arena política a fim de que se desenvolvesse a personalidade adulta desejáveis, forma de controle social e eficiência social. (MOREIRA e TADEU, 2013, p.36).

É, o currículo, uma ferramenta de extrema importância na organização escolar e na execução desta. Moreira (2005), ao discorrer sobre processos curriculares, reforça e defende a ideia de reformulação curricular, não sob um ponto de vista frágil, de se alterar apenas conteúdos e disciplinas, porém de se ir além. Quando fala em mudança, Moreira (2005) reforça a ideia de articulação de aspectos epistemológicos, pedagógicos e políticos. O currículo é movido pelo poder econômico, e não pelo sistema educacional, razão pela qual, diversas vezes o currículo chega pronto aos ambientes de formação e é simplesmente imposto aos profissionais da área da educação.

E a Sociologia do Currículo revela que o currículo deixa de ser um lócus de transmissão de uma cultura incontestável e unitária, de acordo com a visão tradicional, passando a ser visto como um campo em que se tentará impor tanto a definição particular da classe ou grupo dominante quanto ao conteúdo dessa cultura (BOURDIEU, 1979).

Assim, a Teoria Crítica e Sociologia do Currículo situa o currículo como uma arena contestada, uma arena política em que "currículo e ideologia" se intercambiam, passando a Educação como artefato para que a classe dominante transfira sua ideologia para garantir a estrutura social fazendo com que aqueles que saem "antes" (evasão) se apropriem dos valores próprios das classes subalternas em contrapartida os que chegam ao fim (egressos) se apropriem dos mecanismos de dominação. (MOREIRA e TADEU, 2013).

O envolvimento cultura e poder, no contexto de que as relações de poder estão presentes nas relações sociais em que o indivíduo e grupos estão submetidos à vontade ou arbítrio de outros. Relação de sujeição cujos materiais se intercambiam 
e produzem uma política cultural, mas como um terreno de transmissão do conhecimento. O currículo não apenas como campo cultural, mas como campo de construção e produção de significações e, neste sentido, como expressão das relações sociais de poder.

Desta forma, nenhum currículo é neutro ou livre de influências externas, por melhor elaborado seja. A ideologia presente no currículo, e discutida em Moreira e Tadeu (2013) como um aspecto a ser repensado, não pode ser compreendida como um conceito falso. Ideologia, enquanto as divisões que organizam a sociedade e suas relações de poder dessas divisões. Ideologia não enquanto verdadeiro ou falso. Mas pela posição que seus grupos ocupam na organização social. Quais vantagens relativas, na relação de poder, a ideologia justifica ou legitima. A ideologia presente igualmente na didática do professor, nos livros didáticos. Está implícita em rituais e práticas nos arranjos especiais. Os autores afirmam que não se trata de saber se as ideias veiculadas pela ideologia presente no currículo, correspondem ou não à realidade, mas saber a quem essa ideologia beneficia. (MOREIRA e TADEU, 2013).

Sugerem ainda, que há muito a ser discutido e refletido sobre este assunto, que ainda é preciso entender e identificar as relações de poder consistentes no currículo, uma vez que as relações de poder social estão muitas vezes implícitas ou não identificáveis. Os professores, por sua vez, apesar de atrelados às implicações de certa maneira impostas pelo currículo, têm presente em suas atividades o chamado currículo oculto. Além da ideologia, da cultura e do poder, o currículo ainda tem o impacto do currículo oculto, referentes aos aspectos não explicitados no currículo oficial. (MOREIRA e TADEU, 2013).

O currículo oculto, segundo os autores, trata-se do que há em relação às experiências educacionais, mas que não está necessariamente descrito no currículo oficial escolar. O conhecimento envolvido em atividades, por vezes consideradas extracurriculares, abrange a cultura popular, as novas tecnologias e a incorporação dessas manifestações na teoria, não com objetivos apenas mercadológicos, mas também como princípios de igualdade e democracia.

O currículo é a expressão das relações sociais de poder, é a representação dos interesses do poder com vistas, a partir do currículo, constituir-se identidades individuais e sociais, a fim de legitimar e reforçar as relações de poder 
existentes, para que os grupos subjugados continuem subjugados circunscritos ao centro das relações de poder (MOREIRA e TADEU, 2013).

Apple (2008) faz ainda um questionamento acerca da ideologia ao inquirir "qual conhecimento vale mais", como ideia não apenas educacional, mas claramente ideológica e política. Afirma que tal indagação é essencial para discussões educacionais e sociais, uma vez que nela estão envolvidos diversos aspectos e principalmente a formação de cidadãos ativos na sociedade. Os professores são, de certa forma, os grandes responsáveis na formação dos indivíduos e muitas vezes, não têm ideia da imensa responsabilidade que Ihes é incutida, pois acabam sendo também reprodutores rigidamente controlados por esferas políticas e sociais, seguindo demandas que atendam ao mercado de trabalho, não apenas a educação.

Apple (2008) defende a premissa de que enquanto não percebemos que é necessário e imperativo que se leve a sério a intensidade que tem o envolvimento da educação com o mundo real diante das alternantes e desiguais relações de poder, podemos estar vivendo em um mundo divorciado da realidade. Por esta afirmação, podemos refletir que o conhecimento não deve ser tomado como mercadoria. O currículo deve ser elaborado de acordo com demandas e necessidades reais, sociais e globais. O ideal deve ser utópico, pois o que é real ainda é pouco para conseguirmos chegar ao ideal.

Moreira (2005), ainda atribui ao processo de globalização, a origem de fatores de mudanças não apenas nas relações econômicas, mas com reflexos na identidade do sujeito:

A globalização revela-se um intrincado conjunto de processos que operam de maneira contraditória e antagônica atingindo, não apenas os grandes sistemas, como a ordem financeira, como também aspectos íntimos e pessoais. A globalização atinge-nos a todos.". (MOREIRA, 2005, p. 4 e 5).

A globalização atinge a todos e compõem grupos que, de acordo com Moreira (2005) ao tomar as assertivas de Burbules e Torres (2000), a globalização está longe de ser benéfica, aumentado a desigualdade, a exclusão e o desemprego. Há segmentos, que mesmo ante a globalização permanecem intocados, passam a ficar "excluídos" ficam na "base", fragmentados e isolados. A consequência da globalização é um aumento da desigualdade mundial, exclusão social, crescente desemprego, níveis de violência e riscos ecológicos. 
São várias as características da globalização que afetam a educação. A cultura e seus efeitos sobre a educação é uma dessas características. Para Moreira (2005), a partir da virada cultural advinda das mudanças propostas pela década de 1980, com impactos nas ciências sociais, tendendo-se mesmo a que se fale acerca de uma revolução cultural, passa a cultura a corresponder a um processo social constitutivo originando modos de vida distintos e específicos, com reflexos na formação tanto das identidades pessoais, quanto das identidades sociais (WILLIAMS, 1985 e HALL, 1997).

A diversidade cultural, quer no interior de cada estado-nação, quer entre as diferentes partes, caminha-se para uma homogeneização cultural, gerando materiais culturais híbridos. (MOREIRA, 2005).

Moreira (2005) pontua que além do processo da globalização, a que se pensar a renovação curricular, especificamente do ensino superior, numa universidade que esteja situada no campo acadêmico, no campo científico e no campo do currículo.

Para o autor, as responsabilidades sociais da Universidade, por exemplo, não se restringem ao ensino e à pesquisa, mas à abertura à comunidade, ao envolver a sociedade a fim de que seus programas de extensão respondam e se articulem com em seus três distintos campos ao se fundamentar em Pierre Bourdieu: campo do currículo, campo acadêmico e campo científico. Ao adotar os pressupostos de Bourdieu quanto ao conceito de campo (rede, configuração de relação, sistema de posições, na arte, na religião, na ciência, na educação nos esportes) pode-se facear as lutas e histórias no campo ocorridas.

Saviani (2007), pontua que a educação necessita ser conceituada como uma atividade mediadora, no âmago da prática social global, uma vez que a educação pressupõe a união com a tendência de situar-se sob a perspectiva da universalidade, apoiando-se, para tal, no poder da verdade.

Para Macedo (2006), o currículo deve ser pensado como uma arena de produção cultural que esteja além das distinções entre produção e implementação, entre o que é formal e o que deve ser vivido, distinto da cultura escolar e 'cultura da escola', constituindo-se num espaço-tempo em cujas fronteiras, as questões de poder, sejam tratadas sob uma perspectiva de poder menos hierárquica e vertical.

\section{CAMPO CIENTÍFICO}


O conceito de campo científico, conforme formulado por Pierre Bourdieu, facilita a compreensão entre as divergências e as disputas quanto à produção do conhecimento. Moreira (2005) ainda propõe, o emprego do conceito de campo de Bourdieu, como método ou instrumento de análise e não como conceito de teoria.

A noção de campo de Bourdieu traz à tona as lutas que determinados grupos desenvolvem pela manutenção de vantagens e exposições, ou seja, pela preservação de privilégios materiais e símbolos. Um campo é uma rede, é uma configuração de relações objetivas entre posições, é um sistema de posições (CANESIN, 2002).

Bourdieu considera o campo como um universo em que estão inseridos os agentes e as instituições que produzem, reproduzem ou difundem a arte, a literatura e a ciência. (BONNWITZ, 2002)

Num campo tem-se suas leis sociais específicas e seus agentes que atuarão a fim de preservar tal campo onde ocorrem campos de forças e lutas. $\mathrm{O}$ campo é uma rede em que se configuram agentes que se relacionam e formam um sistema de posições.

Moreira (2005), ao apropriar-se e fundamentar-se sobre o conceito de campo cientifico (conforme Bourdieu), dispõe que num campo científico há a distinção do capital científico: seus agentes (fontes do campo) que detêm maior capital científico comanda os pontos de vista, as intervenções científicas, os locais de publicação bem como os objetos a serem investigados.

Todo campo é um campo de forças. Bourdieu, com relação ao campo científico, considera que as relações objetivas entre os diferentes agentes comandam todas as intervenções. E é essa estrutura que comanda o que pode e 0 que não pode ser feito. O capital científico seria um capital simbólico outorgado ou cedido pelos pares no interior do campo. O capital científico é "uma espécie particular de capital simbólico, que consiste no reconhecimento concedido pelos pares no seio do campo". Assim, os que detêm maior capital científico são possivelmente os pesquisadores dominantes que indicam o conjunto de objetos importantes que se deve investigar. (MOREIRA, 2005. p. 13).

Os pesquisadores dominantes são os maiores detentores do capital científico que é o capital humano refinado que, de acordo com as pesquisas 
derivadas da Universidade de Chicago, são as habilidades acumuladas pelos sujeitos ao longo do tempo. O capital científico é o indicador das questões que devem concentrar a atenção dos pesquisadores e, segundo Bourdieu, no interior do campo está sempre em jogo o poder de impor uma definição de ciência.

O campo do currículo por sua vez, é composto por pessoas por vezes ordinárias, por vezes extraordinárias, por pessoas com ideias em constante mudanças (das pessoas e das ideias). Assim, Moreira (2005) sugere que o processo curricular, no Ensino Superior por exemplo, envolva tanto a análise das ideias de currículos quanto as ideias de estudos de currículos numa dada área específica. Apoiado nos conceitos de globalização e campo, Moreira evidencia que o processo de se planejar e orientar a elaboração de currículos no ensino superior demanda subsídios de diferentes fontes e saberes.

\section{MÉTODO}

Por meio da abordagem hipotético-dedutiva que segundo Andrade (2009), fundamenta-se na observação, porém sem se limitar à generalização das observações podendo-se, através deste método, chegar à construção de teorias e leis, o procedimento amparou-se sobre a revisão bibliográfica de textos, livros e artigos em que são discutidos os aspectos de relação de poder e campo e de capital simbólico outorgados e presentes na construção do currículo sob os impactos da globalização. Escolheu-se as produções científico-acadêmicas de Antonio Flavio Barbosa Moreira pela sua influência a partir de Pierre Bourdieu.

\section{CONSIDERAÇÕES FINAIS}

Sendo o currículo, uma ferramenta de extrema importância na organização escolar e na execução desta, a associação do campo do currículo como sendo um instrumento de controle e eficiência social, deixa o currículo de ser um lócus de transmissão de uma cultura incontestável e unitária passando a ser visto como um campo em que se tentará impor tanto a definição particular da classe ou grupo dominante quanto ao conteúdo dessa cultura. A aquisição, o incremento e a solidificação do capital científico proposto pelas ideias de Pierre Bourdieu reforçadas em Moreira, são impactadas pela aquisição do conhecimento, implícito ou explícito 
nos currículos. As relações de poder encontram-se presentes na construção do currículo o qual poderia (ou deveria?) oferecer a possibilidade de se formar elementos capacitados a atuar nos mais diversos âmbitos da sociedade, objetivando oportunidades igualitárias. Há que se pensar numa reforma curricular, seja do ensino superior, seja do ensino básico e fundamental de forma a que a ideologia da classe dominante seja diluída a fim de que a sociedade possa contar com um sujeito capaz de tecer sua própria visão de mundo com identidade individual e social mais legítimas e verdadeiras. O sujeito do mundo globalizado, passível ante a diversidade cultural que se lhe descortina, é vitimado a uma cultura hibrida homogeneizada a despeito de seu estado-nação. É preciso utilizar o currículo, como elemento nivelador das expectativas para a construção de um mundo igualitário e menos heterogêneo. Ao oferecer, portanto, a possibilidade de se formar indivíduos capacitados com vistas às oportunidades igualitárias o currículo constitui-se em si mesmo num campo científico. Apenas desta forma estariam estabelecidas as condições para o verdadeiro e pleno exercício da prática educativa se os atores envolvidos se apoderarem da construção de um currículo capaz de ultrapassar os arcabouços do poder ideológico regulatório.

\section{REFERÊNCIAS}

ANDRADE, M. A. Introdução à Metodologia do Trabalho Científico. 9.ed. São Paulo: Atlas, 2009.

APPLE, M.W., Repensando ideologia e currículo. In: MOREIRA, A. F.; SILVA, T. T. Currículo, Cultura e Sociedade. 10.ed. São Paulo: Cortez, 2008.

BONNEWITZ, P. Pierre Bourdieu: vie, oeuvres, concepts. Paris: Ellipses, 2002

BOURDIEU, P., PASSERON, J. A reprodução: elementos para uma teoria do sistema de ensino, Rio de Janeiro, Livraria Francisco Alves (1975)

BURBULES, N. C.; TORRES, C. A. Globalization and education: an introduction. In: BURBULES, Nicholas C. \& TOREES, Carlos Alberto (eds). Globalization and education: critical perspectives. New York: Routledge, 2000.

CANESIN, M.T. A fertilidade da produção sociológica de Bourdieu para as ciência sociais e a educação. In: ROSA, D. E. G. e SOUZA, V.C. (orgs.). Didática e práticas de ensino: interfaces com diferentes saberes e lugares formativos: Rio de Janeiro: DP\&CA; Goiânia: Alternativa, 2002. 
HALL, Stuart. A centralidade da cultura: notas sobre as revoluções e nosso tempo. Educação \& Realidade. Vol 22. N.2, 1997, p. 15-46.

MACEDO, E. Currículo: Política, Cultura e Poder, Currículo sem Fronteiras, v.6, n.2. pp.98-113, Jul/Dez 2006

MOREIRA, A. F. B.; TADEU, T. Sociologia e teoria crítica do currículo: uma introdução. In: Moreira, A. F.; Tadeu, T. Currículo, cultura e sociedade. 12 ed. São Paulo: Cortez, 2013.

MOREIRA, A. F.B. O processo curricular do ensino superior no contexto atual. In. Veiga, I.P.A., Nave, M.L.P. Currículo e avaliação na educação superior. Araraquara, SP: Junqueira e Marin, 2005.

SAVIANI, D., Escola e Democracia, Polêmicas do nosso tempo, Campinas, Autores Associados, 2007

WILLIAMS, Raymond. Marxism and literature. Oxford: Oxford University Press 1985. 